NASA

Technical Memorandum 103275
AVSCOM

Technical Report 90-C-016

\title{
Computer-Aided Design of High- Contact-Ratio Gears for Minimum Dynamic Load and Stress
}

Hsiang Hsi Lin and Chinwai Lee

Memphis State University

Memphis, Tennessee

and

Fred B. Oswald and Dennis P. Townsend

Lewis Research Center

Cleveland, Ohio

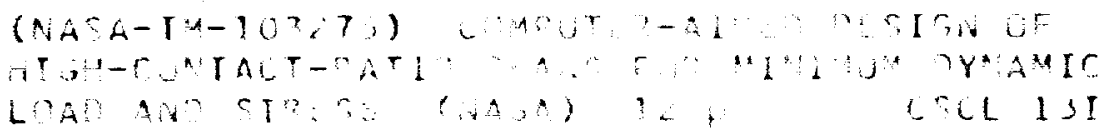

Prepared for the

Design Productivity International Conference

sponsored by the American Society of Mechanical Engineers

Honolulu, Hawaii, February 6-8, 1991

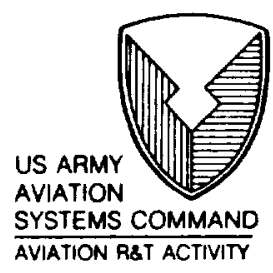



COMPUTER-AIDED DESICN OF HIGH-CONTACT-RATIO CEARS FOR MINIMUM DYNAMIC LOAD AND STRESS

\author{
Hsiang Hsi Lin and Chinwai Lee \\ Memphis State University \\ Memphis, Temnessee 38152
}

and

Fred B. Oswald and Dennis P. Townsend

NASA Lewis Research Center

Cleveland, Ohio 44135

\section{SLMMARY}

This paper presents a computer-aided design procedure for minimizing dynamic effects on high-contactratio gears by modification of the tooth profile. The paper examines and compares both linear and parabolic tooth profile modifications of high-contact-ratio gears under various loading conditions. The effects of the total amount of modification and the length of the modification zone were systematically studied at various loads and speeds to $f$ ind the optimum profile design for minimizing the dynamic load and the tooth bending stress.

Parabolic profile modification is preferred over linear profile modification for high-contact-ratio gears because of its lower sensitivity to manufacturing errors. For parabolic modification a greater amount of modification at the tooth tip and a longer modification zone are required.

Design charts are presented for high-contact-

ratio gears with various profile modifications

operating under a range of loads. A procedure is

illustrated for using the charts to find the optimum profile design.

\section{NOMEYCLATURE}

$\mathrm{C}_{\mathrm{g}}$ damping coefficient of gear tooth mesh, $\mathrm{N}-\mathrm{sec}(\mathrm{lb}-\mathrm{sec})$

$\mathrm{C}_{\mathrm{S}}$ damping coefficient of shaf $\mathrm{t}, \mathrm{N}-\mathrm{m}-\mathrm{sec}$ (lb-in.-sec)

$E_{\mathrm{d}}$

$E_{S}$

$E_{p}$

$E_{t}$ $\mathrm{mm}$ ( in.) positive if material was removed), mm (in.)

static transmission error of gear pair,
HP2DTC

$\mathrm{h}_{\mathrm{L}}$

$h_{\mathrm{S}}$

Ji. IY

$J_{1}, J_{2}$

$\mathrm{k}_{\mathrm{d}}$

$K_{\mathrm{g}}$

$K_{S}$

$L_{n}$

$e_{S}$

$Q^{\mathrm{a}}, \mathrm{Q}^{\mathrm{b}}, \mathrm{Q}^{\mathrm{C}}$

r

$\mathrm{R}_{\mathrm{b} 1}, \mathrm{R}_{\mathrm{b} 2}$

$\mathrm{S}_{\mathrm{n}}$

$\mathrm{T}_{\mathrm{f} 1}, \mathrm{~T}_{\mathrm{f} 2}$ face width of gear teeth. mm (in.)

highest point of second double-tooth contact

tooth thickness at point of load application. mm (in.)

tooth thickness at point of maximum root stress, num (in.)

polar moments of inertia of load and notor. $\mathrm{kg}-\mathrm{nm}^{2}\left(\mathrm{in}-\mathrm{lb}-\mathrm{sec}^{2}\right)$

polar moments of inertia of gear 1 and gear $2, \mathrm{~kg}-\mathrm{mm}^{2}\left(\mathrm{in} .-1 \mathrm{~b}-\mathrm{sec}^{2}\right)$

dynamic factor

stiffness of gear tooth. $\mathrm{V} / \mathrm{mm}(\mathrm{b} / \mathrm{in}$ )

stiffness of shaft, $V-m m / r a d ~(i n .-l b / r a d)$

normalized length of tooth profile modification zone defined such that $L_{n}=1.0$ is length from tooth tip to HP2DTC. measured along line of contact

distance between load point and point of maximum root stress, mm (in.)

combined meshing compliances of tooth pairs $a, b$, and $c$, mun $/ \mathrm{V}(\mathrm{in} . / \mathrm{lb})$

tooth fillet radius, mm (in.)

base radii of gear 1 and gear 2 , mm (in.)

tooth profile error or modification, $\left(E_{p}\right.$ is ( $E_{t}$ is positive if gear 1 leads gear 2$)$, $\mathrm{mm}$ (in.) ratio of maximum static root stress at an applied load to maximum static root stress at design load for unmodified gears

frictional torques on gear 1 and gear 2 . $\mathrm{N}$-mm $($ in. - lb) 


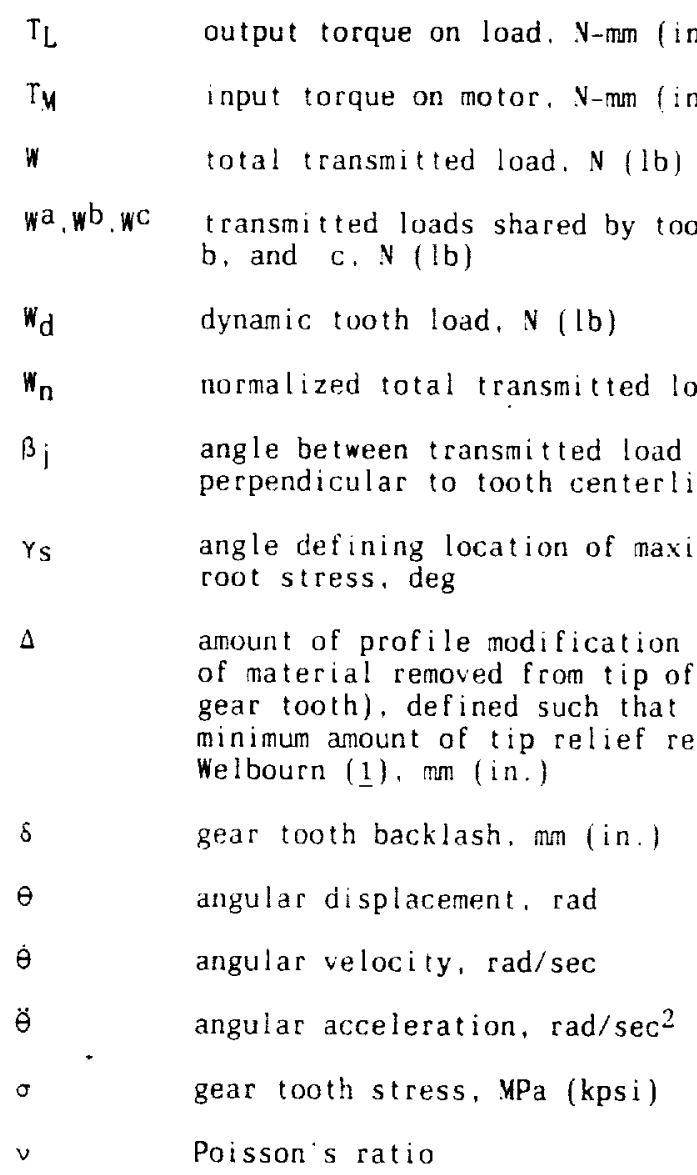

Subscripts:

$\mathrm{i}, \mathrm{i}, \mathrm{k}$ contact point of meshing tooth pairs

1 driving gear

2 driven gear

\section{INTRODUCTION}

Among the goals of advanced gear transmission design are increased life and reliability and reduced weight. The use of high-contact-ratio gears (HCRG) provides an effective means for achieving these goals $(2,3)$. HCRG have at least two pairs of teeth in contact at all times, whereas standard (low contact ratio) gears (LCRG) alternate between one and two pairs in contact. Because the transmitted load is shared by two or more pairs of teeth, the individual tooth load and stress are less for HCRG than for LCRC designs, thereby enabling a higher power-to-weight ratio, longer life, and greater reliability.

HCRG, however, are expected to be dynamically more sensitive to tooth profile modifications (which are commonly applied on modern day gearing for smooth load transfer) because of the multiple tooth contacts (4). Dynamic loads and stress are important concerns in gear performance. High dynamic loads at the tooth contact point will increase gear noise and the risk of surface failure, and high dynamic stress at the tooth root can lead to premature tooth fatigue and fracture. It is essential, therefore, to examine the significance of profile modifications to the dynamics of HCRG and to apply these findings for better transmission designt.
This paper presents a computer-aided design procedure for minimizing the dynamic load and stress of an HCRC system by using profile modifications. The total amount and the length of tooth profile modification were varted $t(t)$ determine their effects on HCRG dynamir:s. Both linear and parabolic modifications were studied, and their individual influence on and relative significance to gear dynamic response are compared and discussed herein.

$t$ set of HCRG that operate at a constant design torque can be optimally modified to minimize dynamic response. For HCRG systems that are to be operated under variable loading, design charts describing the gear dynamic responses for different profile modifications are presented. The optimum length and amount of tooth profile modification for minimum dynamic load and stress can be determined from these charts

\section{THEORETICAL AVALYSIS}

The model of a simple HCRG transmission, including driving and driven gears, two connecting shafts. a motor, and a load, for use in this work has been described in detail in a previous paper (5). Figure 1 shows the theoretical model as a lumped-mass vibration system with four degrees of freedom. Dynamic motions of the model are expressed by the following set of differential equations:

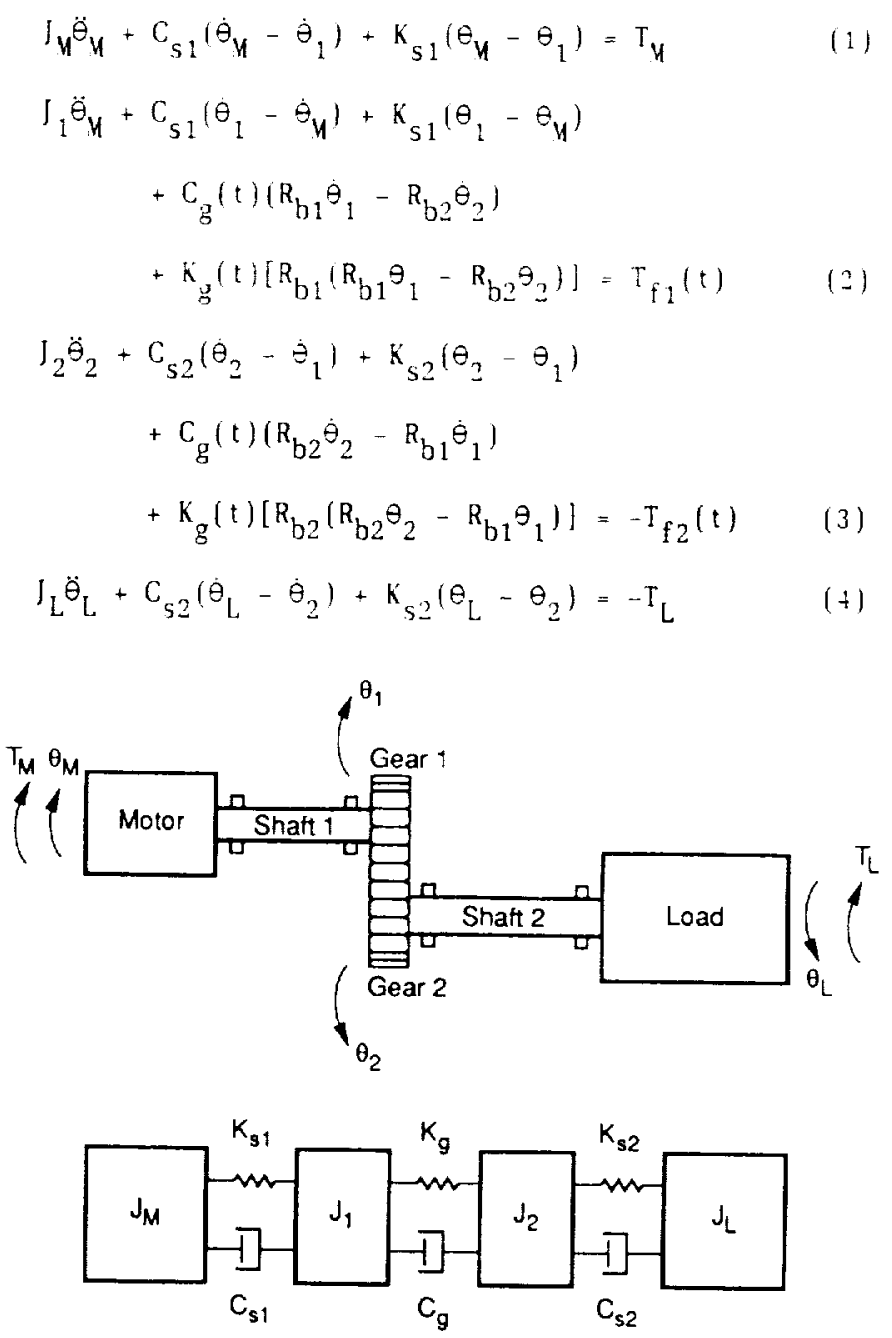

Fig. 1. Simple high-contact-ratio gear transmission system. 
Several assumptions were employed in developing and eventually solving these equations of motion: (1) the dynamic process is defined in the gear rotating plane: (2) no twisting or out-of-plane motion is considered in the equations; (3) contact between gear teeth is along the theoretical line of action; and (t) damping in the system is represented by a constant factor. (The damping factor is expressed as the percentage of critical damping,) From gear literature, typical damping factors of 0.10 and 0.005 , respectively, were chosen for the tooth mesh and for the connecting shafts. The mass moment of inertia and the stiffness of the system can be found from fundamental mechanics principles. A detailed analysis of frictional torque in the gear system was presented in a previous study (6). The equations of motion contain the excitation terms due to the variation of gear meshing stiffness. This meshing stiffness variation is a function of tooth contact position along the line of action and can be affected significantly by tooth profile modification.

\section{Cear Meshing Stiffness and Profile Modification}

The HCRG tooth form with tangent undercut, as presented by Cornell ( 7 ), was used in this investigation. The individual tooth spring stiffness was determined by considering the tooth to be a nonuniform cantilever beam supported by a flexible fillet region and foundation. The combined gear meshing stiffness is the sum of the stiffness of each individual meshing tooth pair. This analysis is limited to HCRG with contact ratios between 2 and 3 . This means there will always be either two or three tooth pairs in contact. For contact ratios higher than 3 , additional equations are required. By designating consecutive meshing tooth pairs in alphabetical order, the static transmission error and the shared tooth load for each individual tooth pair of a triple-tooth contact can be expressed as

$$
\begin{gathered}
\left(E_{t}^{a}\right)_{i}=\left(E_{d 1}^{a}\right)_{i}+\left(E_{d 2}^{a}\right)_{i}+\left(E_{p 1}^{a}\right)_{i}+\left(E_{p 2}^{a}\right)_{i} \\
\left(E_{t}^{b}\right)_{j}=\left(E_{d 1}^{b}\right)_{j}+\left(E_{d 2}^{b}\right)_{j}+\left(E_{p 1}^{b}\right)_{j}+\left(E_{p 2}^{b}\right)_{j} \\
+\left(E_{S 1}^{b}\right)_{j}+\left(E_{S 2}^{b}\right)_{j} \\
\left(E_{t}^{c}\right)_{k}=\left(E_{d 1}^{c}\right)_{k}+\left(E_{d 2}^{c}\right)_{k}+\left(E_{p 1}^{c}\right)_{k}+\left(E_{p 2}^{c}\right)_{k} \\
+\left(E_{S 1}^{c}\right)_{k}+\left(E_{S 2}^{c}\right)_{k} \\
w=w_{i}^{a}+w_{j}^{b}+w_{k}^{c}
\end{gathered}
$$

The superscripts $a, b$, and $c$ indicate the three tooth pairs in contact. The subscripts $i, j$, and $k$ represent different contact points among the three tooth pairs. The contact points are one base pitch apart from each other along the line of action. All the preceding error terms can be converted to linear displacement between the mating gears along the line of action. The static transmission error $E_{t}$ is the total relative displacement of the driven gear with respect to the driving gear along this line. During meshing the static transmission error of the three mating tooth pairs will be the same. Combining and solving the preceding equations simultaneously yields

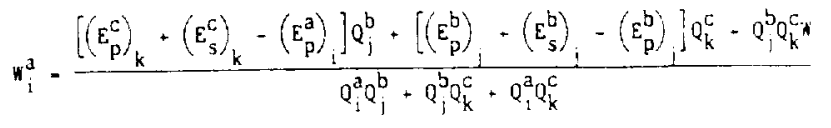

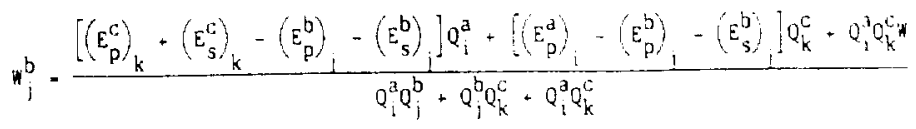

$1 ! 01$

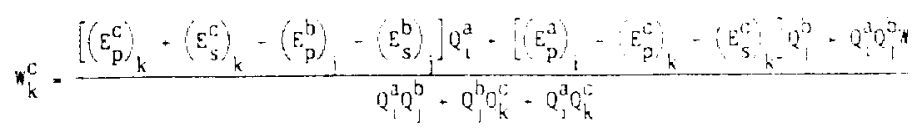

(11)

The gear meshing stiffness $K_{g}$ is the sum of the meshing stiffness of each individual tooth pair and can be expressed at a meshing position of one of the meshing tooth pairs.

$$
\left(k_{g}\right)_{i}=\frac{w_{i}^{a}}{\left(E_{t}^{a}\right)_{i}}+\frac{w_{j}^{b}}{\left(E_{t}^{b}\right)_{j}}+\frac{w_{k}^{c}}{\left(E_{t}^{c}\right)_{k}}=\frac{w}{\left(E_{t}\right)_{i}}
$$

If the terms associated with tonth pair c are eliminated, the preceding equations can be simplified and become the equations for the double-contact region.

Tooth profile modification can be converted to the equivalent linear relative displacement of the mating teeth and incorporated into the profile error terms $E_{p}$ in the preceding equations. Varying the tooth profile will change the gear transmission error and affert the shared tooth load and the gear meshing stiffness. The conventional amount of tip relief has been chosen as a reference value (1) to normalize the amount of profile modification. This conventional amount is equal to the combined tooth deflection from both gears evaluated at the highest point of second double tooth contact (HP2DTC), see Fig. 2(a). If a tooth is modified by this conventional amount, then $\Delta=1.00$. The length of profile modification is designated $L_{n}$. The distance along the tooth profile from the tooth tip to HP2DTC is defined as $L_{n}=1.0$.

The values of $\Delta$ and $L_{n}$ can be varied arbitrarily to obtain any desired combination. Figure 2(a) illustrates a typical HCRG tooth before and after modification. A sample modification chart is shown in Fig. 2(b). On the chart a straight line represents a linear profile modification and a parabolic line represents a parabolic modification. Figure 2 (b) shows two examples each for linear and parabolic profile modifications: (1) $\Delta=1.00$ and $L_{n}=1.00$, and (2) $\Delta=0.50$ and $L_{n}=1.00$.

\section{Dynamic Tooth Load and Root Stcess}

The differential equations of motion were solved by a fourth-order Runge-Kutta Nystrom method ( 8 ) This method employs a linearized iterative procedure by dividing the mesh period into many equal intervals. Initial values of angular displacements were obtained by preloading the input shaft with the nominal torque carried by the system. Initial angular speeds were taken from the nominal system operating speed. For steady-state operation, dynamic motions of the system 


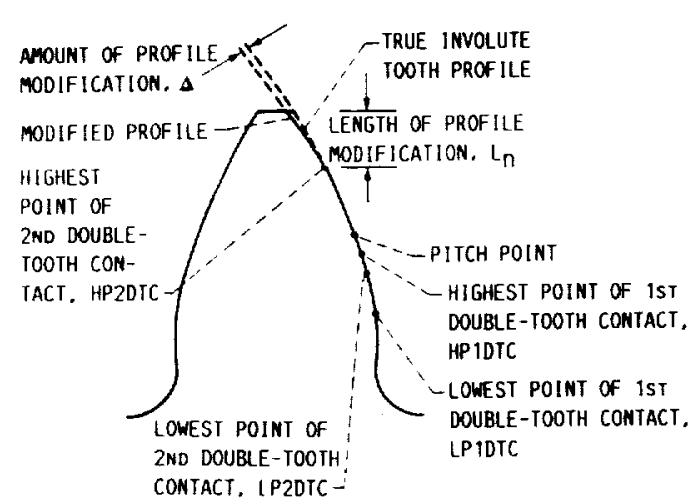

(a) GEAR TOOTH WITH MODIFIED TOOTH PROFIIF.

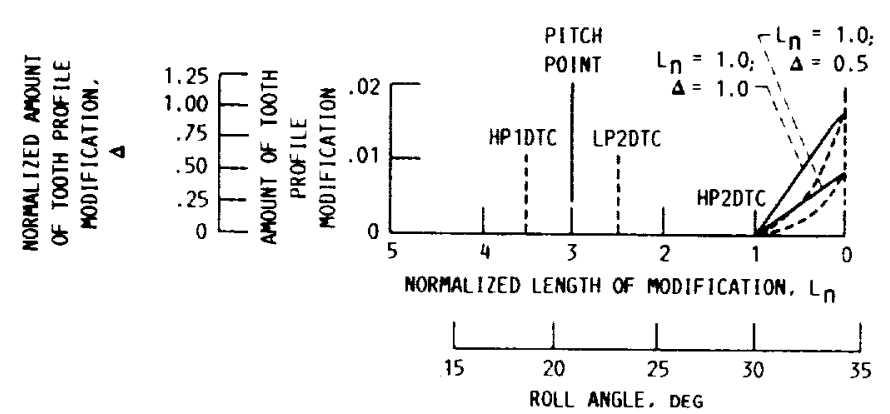

(b) EXAMPLE PROFILE MODIFICATION CHART.

FIGURE 2. - EXAMPLE OF MODIFIED HIGH-CONTACT-RATIO GEAR TOOTH.

can be found from this iterative procedure. A detailed description of the method was presented in (5).

Dynamic tooth load is the product of the relative motions of the gear teeth, $\left(R_{b_{1}} \theta_{1}-R_{b 2} \theta_{2}\right)$ and $\left(R_{b 1} \dot{\theta}_{1}-R_{b 2} \dot{\theta}_{2}\right)$, at contact point i with the corresponding meshing stiffness and damping values. If gear 1 is the driving gear and $\delta$ is the backlash. the following conditions can occur:

Case (i)

$$
\left(R_{b 1} \theta_{1}-R_{b 2} \theta_{2}\right)_{i}>0
$$

This is the normal operating case. The dynamic tooth load $W_{d}$ at point $i$ is then

$$
\begin{aligned}
\left(w_{d}\right)_{i}=\left(K_{g}\right)_{i}\left(R_{b 1} \theta_{1}-\right. & \left.R_{b 2} \theta_{2}\right)_{i} \\
& +\left(C_{g}\right)_{i}\left(R_{b 1} \dot{\theta}_{1}-R_{b 2} \dot{\theta}_{2}\right)_{i}
\end{aligned}
$$

Case (i i)

$$
\left(R_{b 1} \theta_{1}-R_{b 2} \theta_{2}\right)_{i} \leq 0 \text { and }\left|\left(R_{b 1} \theta_{1}-R_{b 2} \theta_{2}\right){ }_{i}\right| \leq \delta
$$

In this case the gears will separate and the contact between the gears will be lost. Hence,

$$
\left(w_{d}\right)_{i}=0
$$

Case ( i i i)

$$
\left(R_{b 1} \theta_{1}-R_{b 2} \theta_{2}\right)_{i}<0 \text { and }\left|\left(R_{b 1} \theta_{1}-R_{b 2} \theta_{2}\right)_{i}\right|>\delta
$$

In this case gear 2 will collide with gear 1 on the back side; then.

$$
\left(W_{d}\right)_{i}=\left(K_{g}\right)_{i}\left(R_{b 2} \ominus_{2}-R_{b 1} \theta_{1}\right)_{i}+\left(C_{g}\right)_{i}\left(R_{b 2} \theta_{2}-R_{b 1} \theta_{1}\right)_{i}
$$

The modif ied Heywood method was used to calculate dynamic tooth root stress from the dynamic loads computed here. This method is considered to be accurate for the HCRG tooth form and gives results that agree well with both finite element analysis and test data (4). The modified Heyword formula for tooth root stress is

$$
\begin{gathered}
\sigma_{i}=\frac{\left(w_{d}\right)_{i} \cos \beta_{i}}{F}\left[1+0.26\left(\frac{h_{s}}{2 r}\right)^{0.7}\right]\left[6 \frac{\ell_{s}-\left(\frac{h_{L} \tan \beta_{i}}{2}\right)}{h_{s}^{2}}\right. \\
\left.+\left(\frac{0.72}{h_{s}{ }_{s}}\right)^{0.5}\left(1-\frac{h_{L}}{h_{s}} v \tan \beta_{i}\right) \frac{\tan \beta_{i}}{h_{s}}\right]
\end{gathered}
$$

where $v \approx 1 / 4$, according to Heywood; $\beta_{i}$ is the load angle; $F$ is the face width; $r$ is the fillet radius: and $h_{L}$ is the tooth thickness at the load point. see Fig. 3. The values of $h_{S}$ and $\ell_{s}$ are related to the gear tooth geometry, the load position, and the point of maximum stress in the fillet. The magnitude of $Y_{S}$, which defines the position of maximum $f$ illet stress, varies with the fillet radius $r$, the load position, and the thickness of the tooth's thinnest section (4) . For a typical LCRG tooth $Y_{s}=30^{\circ}$ is considered to be a reasonable average value. However. for HCRG it is more appropriate to use $20^{\circ}$ as an average value of $Y_{S}$. A detailed analysis for finding values of $\ell_{S}$ and $h_{S}$ is provided in (it).

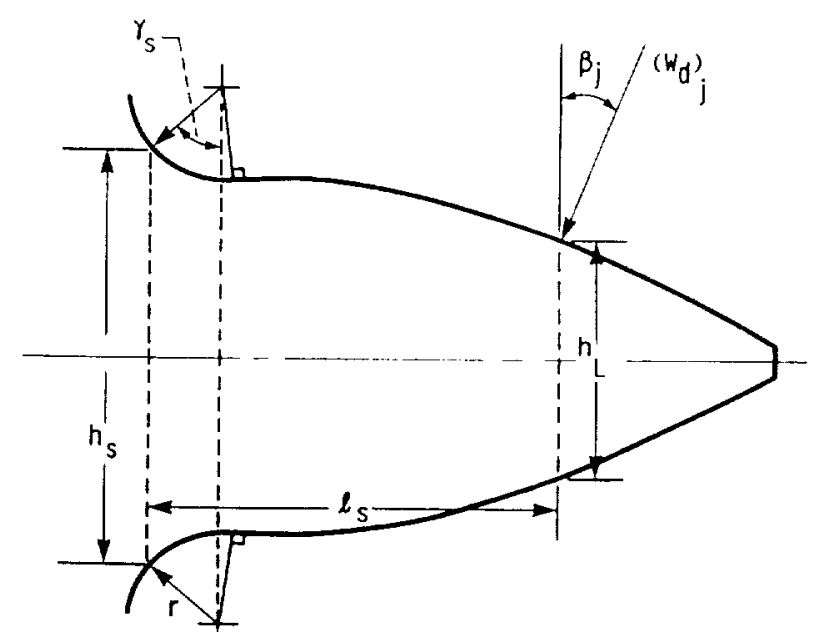

FIGURE 3. - GEAR TOOTH GEOMETRY FOR ROOT STRESS CALCULATION. 


\section{RESULTS AND DISCUSSION}

A typical high-contact-ratio gear set, as specified in Table I, was used for the analysis. These were identical involute spur gears with addendum extended, about 53 percent longer than the standard value, to achieve a high tooth contact ratio. The standard contact ratio is 1.64. After the addendum extension the contact ratio was 2.40 . The connecting shafts were $305 \mathrm{~mm}(12 \mathrm{in.})$ long and $25.4 \mathrm{~mm}(1 \mathrm{in.})$ in diameter. Mass moments of inertia of the motor and the load were assumed to be 70 times and 50 times the gear inertia, respectively. The gears and shafts were made of steel.

THBLE 1. - CEAR OATA

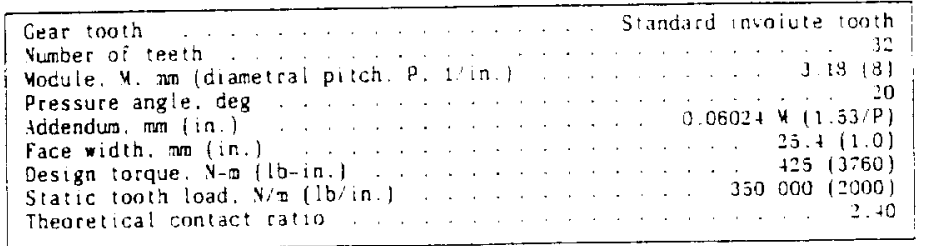

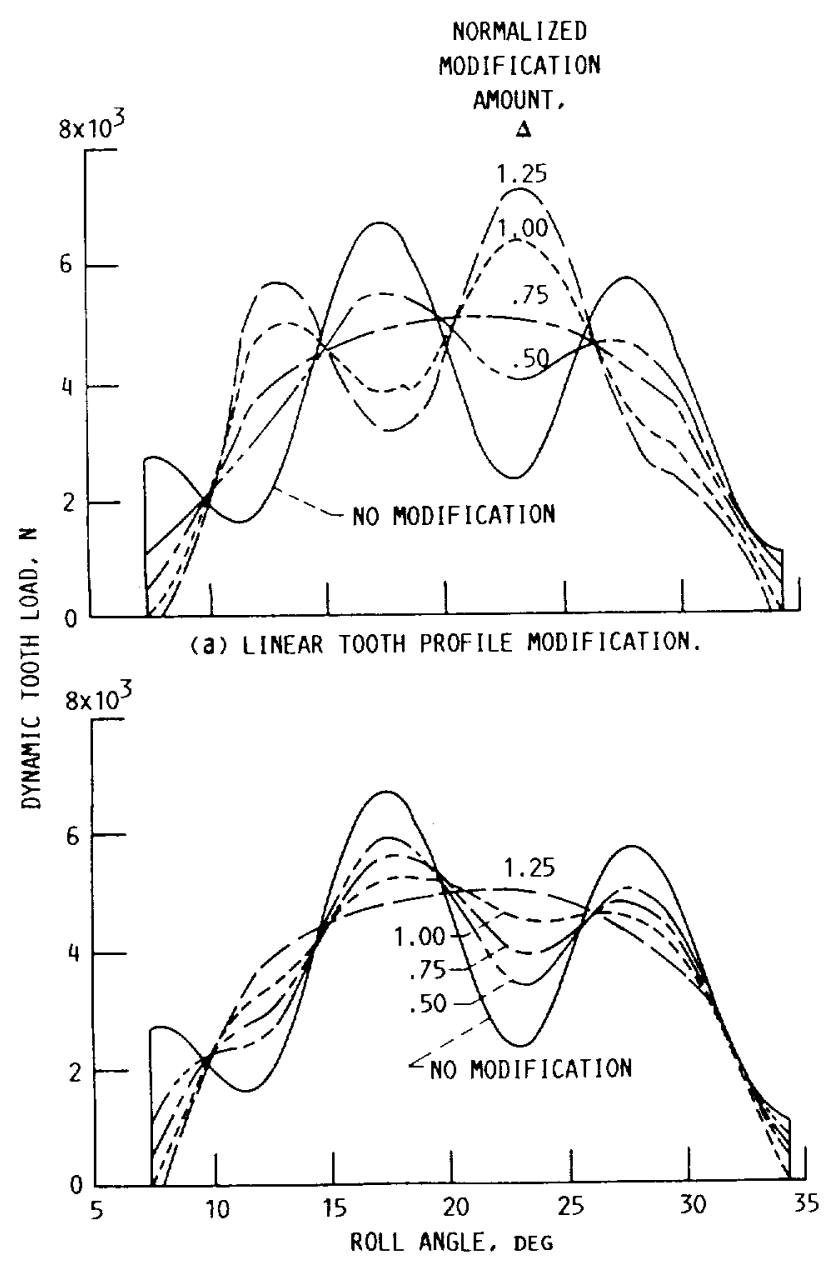

(b) PARABOLIC TOOTH PROFILE MODIFICATION.

FIGURE 4. - VARIATION OF DYNAMIC TOOTH LOAD WITH GEAR ROLL ANGLE AT 8500 RPM. FULL DESIGN LOAD, $L_{n}=1.00$. AND VARYING $\Delta$.
Two types of tooth profile modification. linear and parabolic, were applied on the gear teeth. In this study the same amount and the same length of profile modification were applied to the tooth tip of both pinion and gear. To examine their effects on peak dynamic response, we varied the total amount of modification and the length of the modification zone systematically. The input torque on the gear set was also varied to determine its influence on the dynamics of the modified gears.

\section{Effects of Tooth Profile Modification}

Figure 4 shows the HCRG dynamic tooth load as a function of gear roll angle at the speed of $8500 \mathrm{rpm}$. This speed is near the system natural frequency (9300 rpm, (5)) and was expected to produce sufficiently high dynamic response for our evaluation. The HCRG were studied at four different amounts of profile modification $(\Delta=0.50 .0 .75,1.00$, and 1.25$)$ and with the modification length held constant at $L_{n}=1.00$. The applied load was the full design load (350 $000 \mathrm{~V} / \mathrm{m}$. or $2000 \mathrm{lb} / \mathrm{in.}$. As shown in Figs. $4(\mathrm{a})$ and (b) any of the modifications helped to relieve the impact bump at the beginning of the tooth engagement, which helped to reduce the subsequent peak dynamic load during the mesh cycle. Linear modification at the conventional amount or greater $(J=1.00$ or 1.25$)$ produced significant dynamic peaks, whereas parabolic modification at these amounts created a smooth dynamic response. This result shows that linear profile modification requires less than the conventional amount of modification $(\Delta<1.00)$ but parabolic modificat ion requires more than the conventional amount $(\Delta>1.00)$ to achieve lower dynamic load.

The amount of profile modification was systematically varied to examine its effect on the dynamic stress of HCRG. Figure 5 shows the variation of the dynamic tooth root stress of the driving gear under the same operating conditions as in Fig. 4. This figure demonstrates that a reduced amount is beneficial for linear profile modification, whereas an increased amount is better for parabolic modification.

Figure 6 presents a speed sweep plot of the dynamic load factor and dynamic stress factor for gears with parabolic tooth profile modification. The dynamic load factor is defined as the ratio of maximum dynamic tooth load during contact to total static load. This dynamic load factor for HCRG is typically less than unity because the load is shared by the two or more tooth pairs in mesh. The dynamic stress factor is defined as the peak dynamic root stress divided by the peak static root stress of the unmodified case. This factor is generally greater than unity because the maximum dynamic stress is greater than the static tooth stress.

The solid curves in Figs. 6(a) and (b) represent the response of unmodified gears. Note that there is a prominent peak for both dynamic tooth load and dynamic root stress at $9300 \mathrm{rpm}$. the primary critical speed of this HCRG transmission. Properly chosen profile modification can reduce this dynamic peak considerably. as illustrated in Fig. 6. Comparison of Figs. 6(a) and (b) reveals that the magnitude of the profile modification $\Delta$ has a greater effect in controlling the dynamic stress than the dynamic load. Over most of the speed range surveyed, gears modified with $L_{n}=1.00$ and $\Delta=1.25$ yielded the minimum dynamic load and stress.

A change in tooth profile affects not only the maximum tooth load, but also the position of the maximum load (the moment of the load) on the tooth. Both 


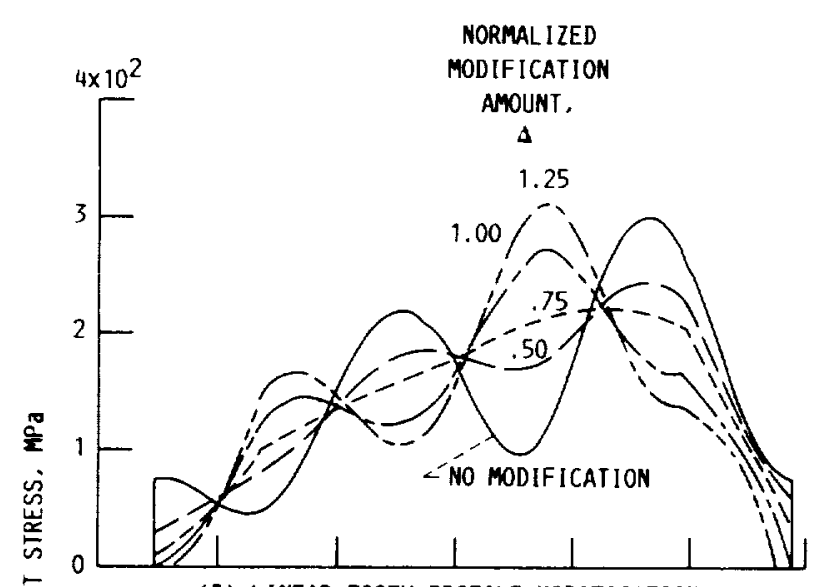

(a) LIMEAR TOOTH PROFILE MODIFICATION.

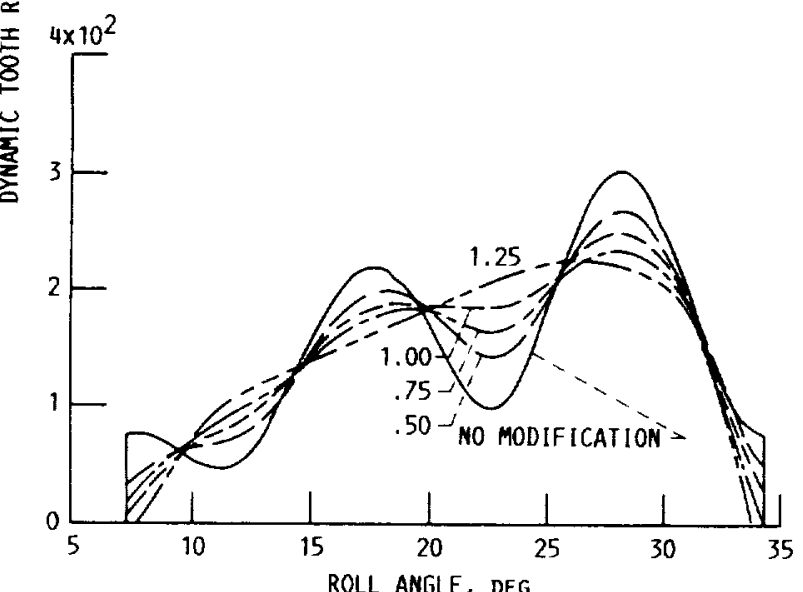

(b) PARABOLIC TOOTH PROFILE MODIFICATION.

FIGURE 5. - VARIATION OF DYMAMIC TOOTH ROOT STRESS WITH GEAR ROLL ANGLE AT 8500 RPM. FULL DESIGN LOAD. $L_{n}=1.0$. AND VARYING $\Delta$.

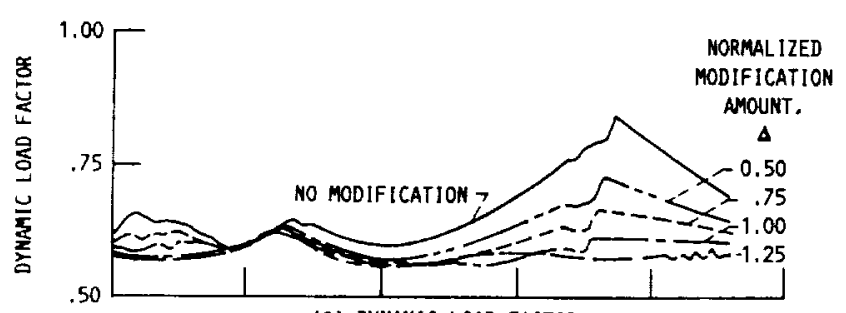

(a) DYMAMIC LOAD FACTOR.

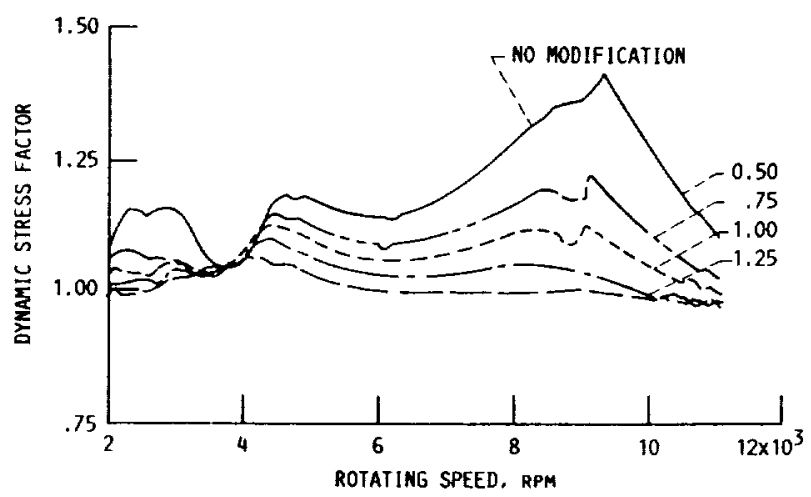

(b) DYMAMIC STRESS FACTOR.

FIGURE 6. - VARIATION OF GEAR DYMAMIC LOAD FACTOR AND DYMAMIC STRESS FACTOR WITH ROTATING SPEED AT FULL DESIGN LOAD, PARABOLIC TOOTH PROFILE MODIFICATION, $L_{n}=1.00$. AND VARYING $\Delta$. of these effects contribute to the magnitude of dynamic tooth root stress. Therefore, the optimum profile modification for minimizing the dynamic load might be different from the optimum profile modification for minimizing the dynamic tooth root stress. A similar analys is for linear modification is reported in (5). Because of varying power demands gear transmissions are generally required to operate over a range of loads. Since the preferred tooth profile for one design load (torque) may not be a good solution for a different load. it is more practical to design a tooth profile that will work well under various operating loads than at a single load.

\section{Gear Tooth Design for Minimum Dynamic Load}

Figures $7(a)$ and (b) illustrate, for both linear and parabolic profile modification, the effect of varying the amount of profile modification (at constant length $L_{n}=1.00$ ) on the normalized maximum dynamic load of HCRG. Results are presented for several applied loads ranging from 70 to 120 percent of the design load. Each figure comprises data from more than 50 speed sweeps of HCRG dynamics. The normalized maximum dynamic load is defined as the product of the maximum dynamic load factor (KDLF) and the normalized applied load $W_{n}$, where $W_{n}$ is the ratio of the actual applied load to the design load of $350000 \mathrm{~N} / \mathrm{m}$ $(2000 \mathrm{lb} / \mathrm{in.})$. If the applied load equals the design load, $W_{n}=1.00$. This normalized value is used to illustrate the absolute dynamic response of the HCRG system. It is useful for comparing the benefit of various tooth profile modifications at different applied loads. The actual value of the dynamic tooth load may be found by multiplying the normalized value by the design load.

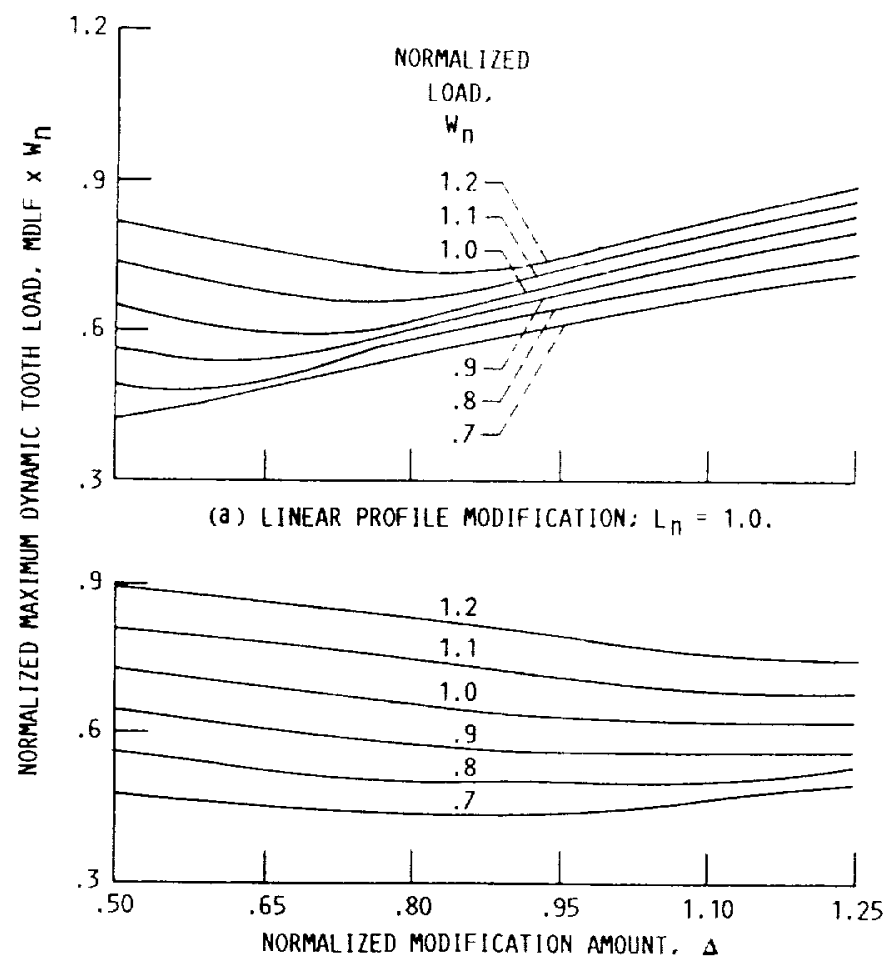

(b) PARABOLIC PROFILE MODIFICATION: $L_{n}=1.0$.

FIGURE 7. - EFFECT OF AMOUNT OF PROFILE MODIFICATION ON NORMALIZED MAXIMUM DYNAMIC TOOTH LOAD AI VARIOUS NORMALIZED LOADS. 
Comparison of the curves in Figs. 7 (a) and (b) reveals that the curves for HCRC with linear modification (Fig. $7(a)$ ) are more affected by changes in modification amount $\Delta$. The curves for parabolic modification (Fig. 7(b)) change little with the modification amount but are more sensitive to the change in applied load $W_{n}$. The modification amount required to minimize the dynamic response at each individual load can be read from the appropriate load curve in Fig. 7 . In general, over the load range surveyed, linear modification requires less than the conventional amount $(\Delta<1.00)$ and parabolic modification requires more than the conventional amount $(\Delta>1.00)$ to minimize dynamic load.

Figures $8(a)$ and (b) show the effect of the length of profile modification (with constant modification amount $\Delta=1.00$ ) on the normalized maximum dynamic load of HCRG. Comparing Figs. 7 and 8 shows that dynamic load curves vary more with respect to the length of profile modification $L_{n}$ than with respect to the amount $\Delta$. This indicates that the length of profile modification has a more prominent influence on HCRG dynamics. [n addition, the minimum point of the dynamic load curves due to a change in $s$ has a wider

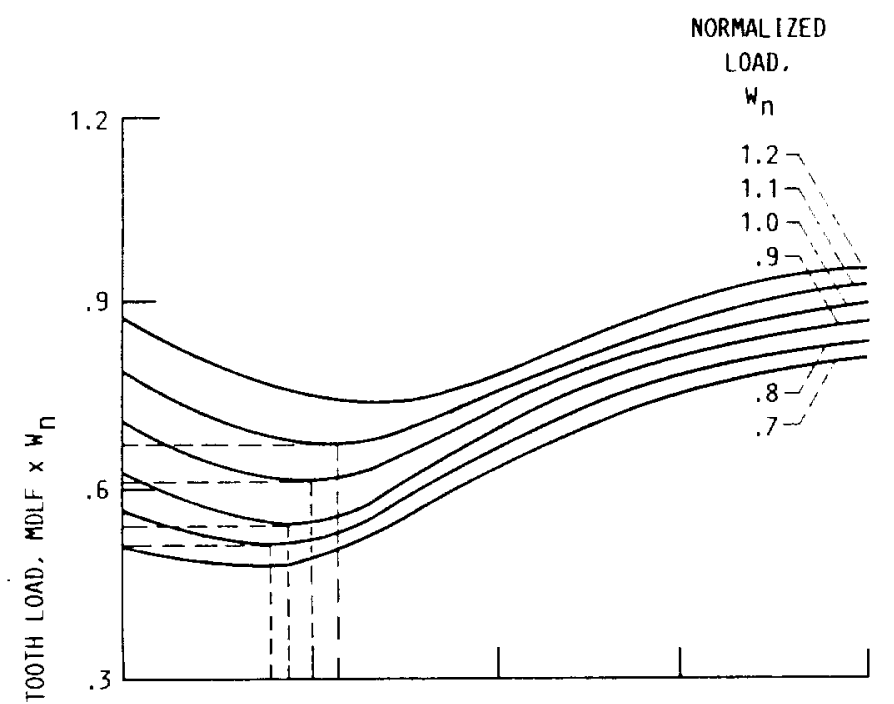

(a) LINEAR PROFILE MODIFICATION; $\Delta=1.0$.

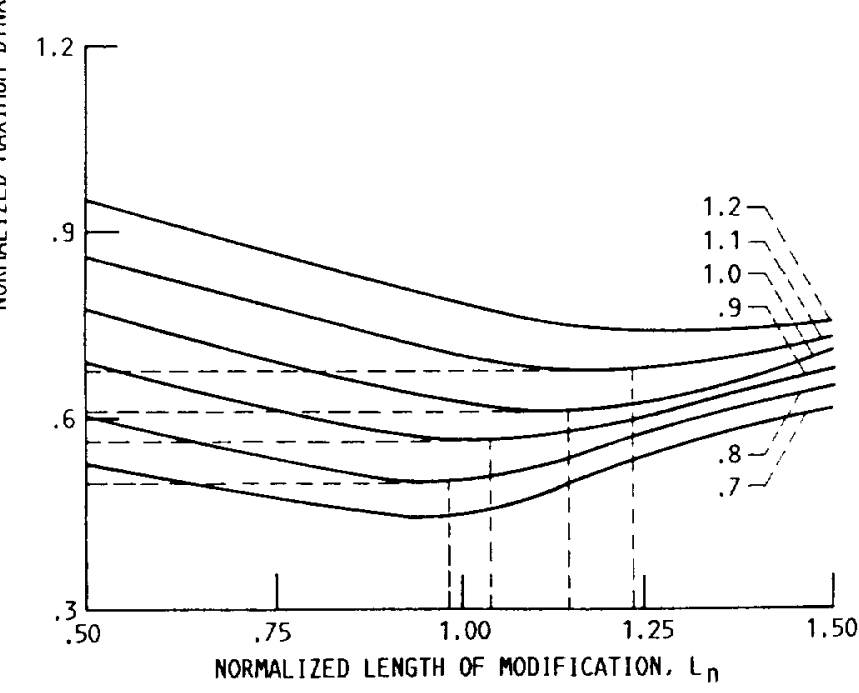

(b) PARABOLIC PROFILF MODIFICATION: $\Delta=1.0$.

FIGURE 8. - EFFECT OF LENGTH OF MODIFICATION ZONE ON NORMAL IZED MAXIMUM DYNAMIC TOOTH LOAD AT VARIOUS LOADS. spread than that due to changes in $L_{n}$. This effect is illustrated in Figs. 7 and 8 . For linear modification (Fig. $7(a)$ ) the values of $\triangle$ that produced the minimum normalized dynamic load are $0.50,0.56,0.62$ $0.69,0.75$, and 0.84 . respectuely. over the load range studied. $W_{n}$ of 0.7 to 1.2. This means that the optimum values for the amount of profile modification change by 0.34 for this range of $W_{n}$. Likewise, in Fig, $8(a)$ the values of the length of modification $L_{n}$ that produced the minimum normalized dynamic load over the same load range are $0.67,0.70,0.72,0.75,0.78$. and 0.82 , cespectively. For this range of loading the optimum value of $L_{n}$ varied by only 0.15 . This implies that for linear modification the length of morif ication should be more closely controlled because it has a more dramatic effect on the dynamic load

In a similar study for gears with parabolic modi fication, there was little change in dynamic load with changes in the modification amount (Fig. $7(b))$ and only a small change in dynamic load with changes in the modification length (Fig. 8(b)). Therefore. HCRG with parabolic modification should be less affected by manufacturing tolerances and machining errors than HCRG with 1 inear modif ication.

Since the length of modification has a greater effect on HCRG dynamic loads than does the amount of modification, a better HCRG tooth profile can be designed, for any range of applied load, by holding the amount $\triangle$ constant while varying the length $b_{n}$ to find the optimum values. To determine these optimum values, the designer may plot several curves (such as in Fig. 8) and find the best modification length $L_{n}$ and the normalized maximum dynamic load for each curve. The normalized load multiplied by a time distribution factor is then divided by the sum of the product of normalized load and time distribution factor for all curves to form a weighting factor for the modification length.

As an example, consider the load range from $W_{n}$ of 0.80 to $1.10 \mathrm{in} \mathrm{Fig.} \mathrm{8.} \mathrm{assuming} \mathrm{that} \mathrm{the} \mathrm{dis-}$ tribution of time at each load level is $10,30,50$. and 10 percent, respectively. For linear modification in Fig 8(a), values of minimum normalized load and the corresponding $L_{n}$ for each load are found from the load curves. Dashed lines in Fig. $8(a)$ illustrate the data for this example. The data are also listed in Table II. The weight for each curve is deternined by taking the product of the normal load and time distribution factors and then dividing by the sum of similar products for all curves. Thus for the $W_{n}=0.80$ curve, the weight is $(0.52 \times 0.10) /(0.52 \times 0.10+0.55 \times$ $0.30+0.61 \times 0.50+0.67 \times 0.10)=0.088$. This value is then multipied by the $L_{n}$ value for this curve to produce a weighted $L_{n}$. For $W_{n}=0.80$ the weighted $L_{n}$ is $0.088 \times 0.70=0.062$. Finally, all of the weighted $L_{n}$ values are added together to give the desired optimum $L_{n}$ for the load range. In this case the final value of weighted $L_{n}$ equals 0.74 . This is

THBLE II. - EXAYPLE DATA FOR CALCLLATIY OPTIUI L LENTHE OF

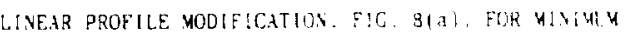
DYvante, IOUTH DOtO

\begin{tabular}{|c|c|c|c|c|c|}
\hline $\begin{array}{c}\text { Wormalized } \\
\text { tolal } \\
\text { transmilted } \\
\text { load } \\
w_{n}\end{array}$ & $\begin{array}{l}\text { Normalized } \\
\text { length } \\
\text { of tooth } \\
\text { profile. } \\
L_{n}\end{array}$ & $\begin{array}{l}\text { Normal:zed } \\
\text { maximum } \\
\text { dynamic load }\end{array}$ & $T: m$ & height & Welghted \\
\hline $\begin{array}{r}0.80 \\
.90 \\
1.00 \\
1.10\end{array}$ & $\begin{array}{l}0.70 \\
.72 \\
.75 \\
.78\end{array}$ & $\begin{array}{r}0.52 \\
53 \\
61 \\
67\end{array}$ & $\begin{array}{r}0.10 \\
.30 \\
.50 \\
.10 \\
.00\end{array}$ & $\begin{array}{r}0.088 \\
.230 \\
.518 \\
114 \\
1.000\end{array}$ & $\begin{array}{r}0.063 \\
.201 \\
.389 \\
.083 \\
0.74\end{array}$ \\
\hline
\end{tabular}


the best value of $L_{n}$ for the load range $W_{n}$ of 0.80 to 1.10 with the time weighting as specified.

As a second example. the optimum parabolic profile modification was found for the same load range and procedure used in the first example. This is illustrated in Fig. $8(\mathrm{~b})$ and the data are shown in Table III. The optimum $L_{n}$ for this case is 1.10 . The normalized maximum dynamic load values created by this optimum parabolic profile modification $(\Delta=1.00$, $\left.L_{n}=1.10\right)$, for $W_{n}$ of 0.80 to 1.10 , is in the range 0.53 to 0.68 , which is almost exactly the same as that created by the optimum linear profile modification $\left(\Delta=1.00, L_{n}=0.74\right)$. For the goal of minimizing dynamic load, there is little difference between linear and parabolic modification. Nevertheless, parabolic modification appears to be less sensitive to manufacturing variance and is therefore preferred to linear modification.

TABLE III. - EXAMPLE DATA FOR CALCULATISG OPTIMLM LENCTH OF PARABOLIC PROFILE WODIFICATION, FIG. B(b), FOR MINIVCY DYNAYIC TOOTH LOAD

\begin{tabular}{|c|c|c|c|c|c|}
\hline $\begin{array}{c}\text { Yormalized } \\
\text { lotal } \\
\text { transmitted } \\
\text { load, } \\
w_{n}\end{array}$ & $\begin{array}{c}\text { Normalized } \\
\text { length } \\
\text { of tooth } \\
\text { profile, } \\
L_{n}\end{array}$ & $\begin{array}{c}\text { Normalized } \\
\text { maximum } \\
\text { dynamic load }\end{array}$ & Time & Weight & $\begin{array}{c}\text { Weighted } \\
L_{n}\end{array}$ \\
\hline 0.80 & 0.98 & 0.50 & 0.10 & 0.085 & 0.083 \\
.90 & 1.03 & .56 & .30 & .285 & .294 \\
1.00 & 1.14 & .61 & .50 & .517 & .589 \\
1.10 & 1.22 & .67 & $\frac{10}{1.00}$ & $\frac{.13}{1.000}$ & $\frac{.138}{\approx 1.10}$ \\
\hline
\end{tabular}

\section{Cear Tooth Design for Minimum Dynamic Stress}

The peak dynamic tooth stress depends on both the magnitude of the peak dynamic load and its location along the tooth surface. Therefore, the optimum tooth profile that minimizes peak dynamic stress may not be the same as that which minimizes peak tooth load. By applying an analysis similar to that in the preceding section, we can design a gear tooth profile that will minimize dynamic tooth stress for the HCRG operating over a range of loads.

Figures 9 and 10 show the effects of the amount and length of tooth profile modification on the normalized maximum dynamic stress for several applied loads. The normalized maximun dynamic stress is the product of the maximum dynamic stress factor (MDSF), obtained from the speed sweep, and the normalized static root stress $S_{n}$, where $S_{n}$ is the ratio of maximum static root stress at one value of applied load to the maximum root stress at the design load for unmodified gears. The actual value of dynamic tooth root stress can be found by multiplying the normalized value by the maximum static root stress at design torque. Similar trends were found from Figs. 9 and 10 as were found from Figs. 7 and 8: (1) the dynamic response of modified HCRG is affected more by the variation of $L_{n}$; (2) parabolically modified gears are more sensitive to changes in load; and (3) linearly modified gears are more affected by both the length and amount of profile modification than are gears with parabolic modification.

Because the length of modification has a more prominent influence, we can hold the modification amount constant at $\Delta=1.00$ and vary the length $L_{n}$ to minimize the dynamic stress of HCRG. The stress curves in Fig. 10 can be used as design curves for choosing optimum values of the modification length $L_{n}$. As in the last example, we assume the gears will operate in the $W_{n}$ range 0.80 to 1.10 , and we assume the same distribution of time at each load level as before. The best value of $L_{n}$ can be obtained for

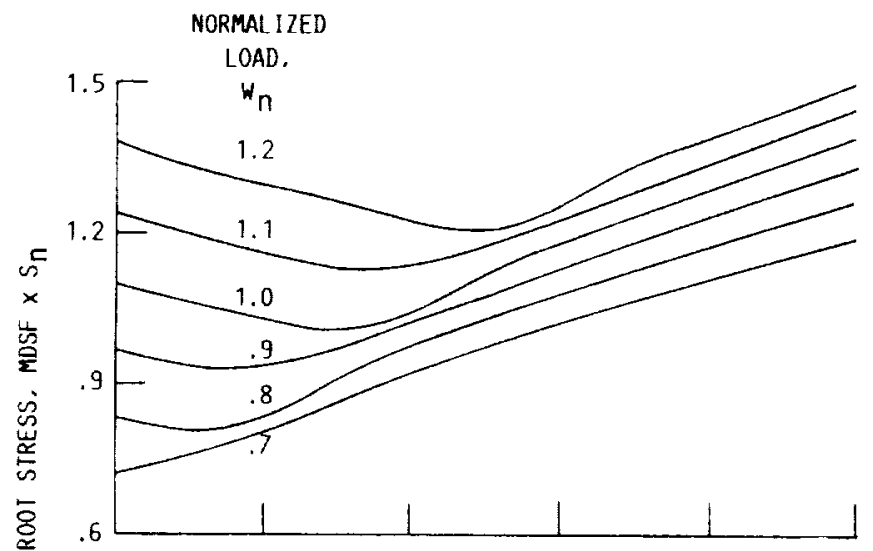

(a) LINEAR PROFILE MODIFICATION; $L_{n}=1.0$.

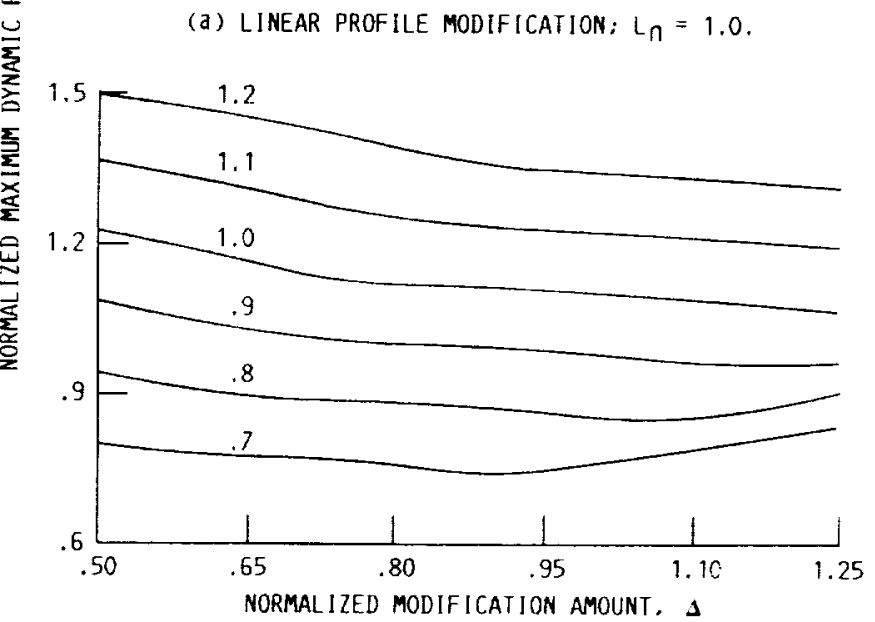

(b) PARABOLIC PROFILE MODIFICATION: $L_{n}=1.0$.

FIGURE 9. - EFFECT OF AMOUNT OF PROFILE MODIFICATION ON NORMALIZED MAXIMUM DYNAMIC ROOT STRESS AT VARIOUS NORMALIZED LOADS.

linear and for parabolic tooth profile modification. Table IV shows the data and the calculated optimum $L_{n}$ value for linear modification. The opt imun value is $L_{n}=0.76$. Table $V$ shows the result for parabolic profile modification. The optimum length for the parabolically modified gears is $L_{n}=1.17$. Comparing these results with the results of the preceding section, we find that the optimum length of profile modification required for minimum dynamic root stress is approximately 3 to 4 percent longer than that for minimum dynamic tooth load.

The normalized dynamic stress values of the optimized gears, for the load range considered, are about the same with either linear or parabolic profile modification. However, parabolic modification is preferred over linear modification because of its lower sensitivity to manufacturing errors.

\section{CONCLUSIONS}

A computer-aided design procedure to minimize the dynamic effects of high-contact-ratio gears through modification of the gear tooth profile has been illustrated. The method presented may be used as a design tool for optimizing the tooth profile of high-contactratio gears that operate over a range of loads. Selec$t i o n$ of the best gear tooth profile depends on the type of tooth profile modification chosen, the range of the applied loads, and the allocation of service time among the loads. 


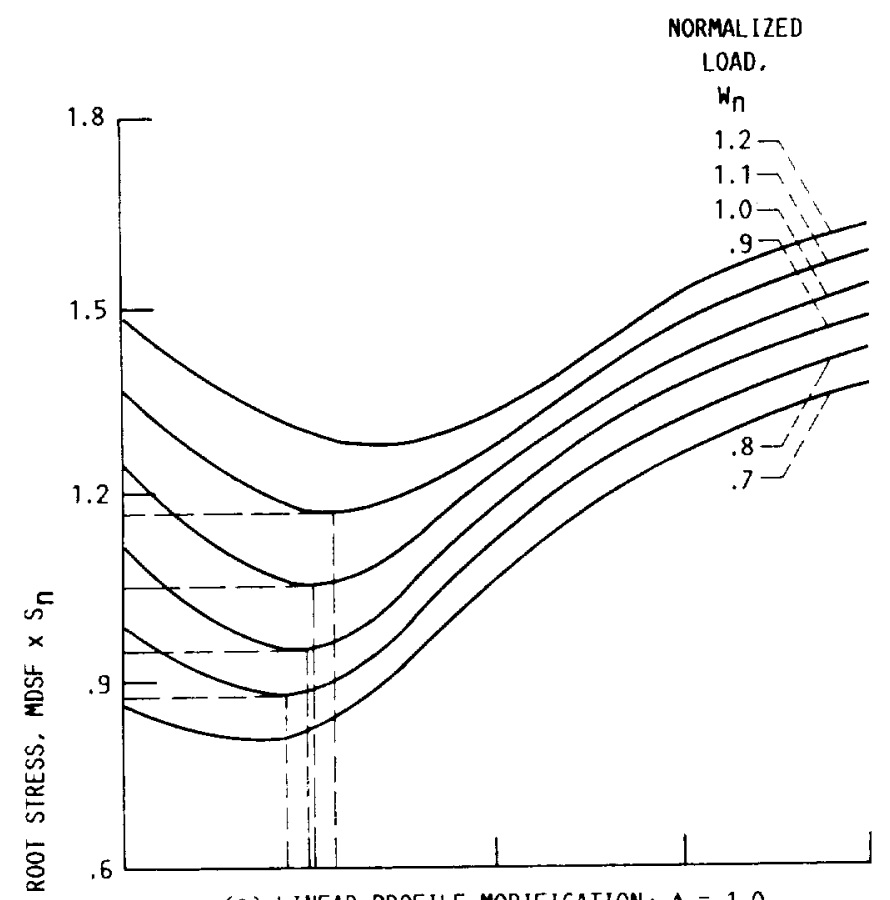

(a) LINEAR PROFILE MODIFICATION: $\Delta=1.0$.

1.5

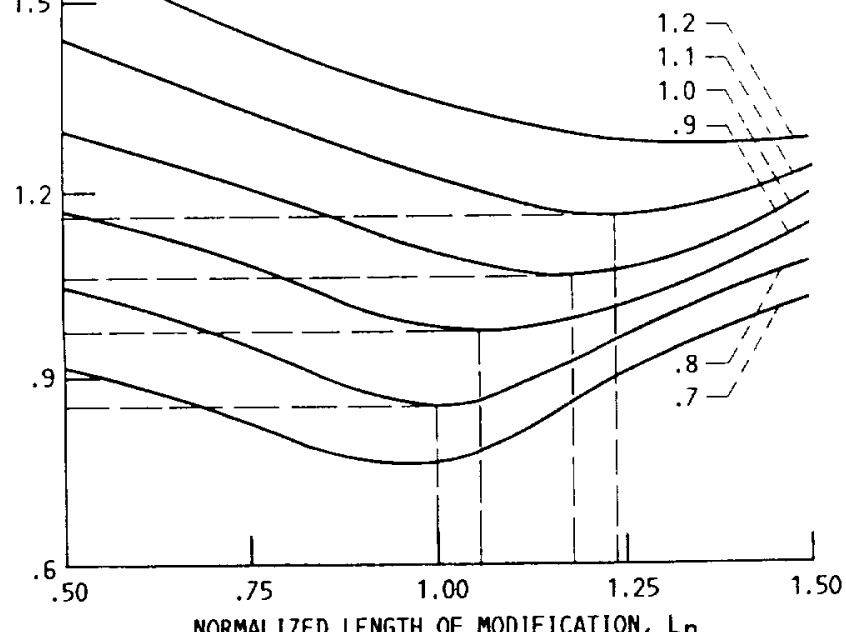

(b) PARABOLIC PROFILE MODIFICATION: $\Delta=1.0$.

FIGURE 10. - EFFECT OF LENGTH OF MODIFICATION ZONE ON NORMAL IZED MAXIMUM DYNAMIC ROOT STRESS AT VARIOUS LOADS.

TABLE IV. - EXAMPLE DATA FOR CALCULATING OPTIMLY LEXCTH OF LINEAR PROFILE MODIFICATION, FIC. 1O(a), FOR MINIMLM DYYAMIC ROOT STRESS

\begin{tabular}{|c|c|c|c|c|c|}
\hline $\begin{array}{c}\text { Normalized } \\
\text { total } \\
\text { transmitted } \\
\text { load. } \\
w_{n}\end{array}$ & $\begin{array}{c}\text { Normalized } \\
\text { length } \\
\text { of tooth } \\
\text { profile. } \\
\mathrm{L}_{\mathrm{n}}\end{array}$ & $\begin{array}{c}\text { Normalized } \\
\text { maximum } \\
\text { dynamic stress }\end{array}$ & Time & $\begin{array}{c}\text { Weight } \\
\mathrm{L}_{\mathrm{n}}\end{array}$ & $\begin{array}{c}\text { Weighted } \\
L_{n}\end{array}$ \\
\hline 0.80 & 0.72 & 0.88 & 0.10 & 0.089 & 0.064 \\
.90 & .75 & .95 & .30 & .289 & .217 \\
1.00 & .76 & 1.00 & .50 & .508 & .386 \\
1.10 & .80 & 1.12 & $\frac{.10}{1.00}$ & $\frac{.114}{1.000}$ & $\frac{.091}{\approx 0.76}$ \\
\hline
\end{tabular}

TABLE V. - EXAMPLE DATA FOR CALCLLATING OPTIMLY LENGTH OF PARABOLIC PROFILE MODIFICATION, F!C, LO(b), FOR YINIMUY DYNAHIC RCOT STRESS

\begin{tabular}{|c|c|c|c|c|c|}
\hline $\begin{array}{c}\text { Normalized } \\
\text { tolal } \\
\text { transmitted } \\
\text { load, } \\
w_{n}\end{array}$ & $\begin{array}{c}\text { Normalized } \\
\text { length } \\
\text { of tooth } \\
\text { profile. } \\
L_{n}\end{array}$ & $\begin{array}{c}\text { Sormailzed } \\
\text { maximim } \\
\text { dynamic stress }\end{array}$ & Гine & Helgnt & 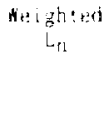 \\
\hline $\begin{array}{r}0.80 \\
.90 \\
1.00 \\
1.10\end{array}$ & $\begin{array}{r}1.00 \\
1.06 \\
.18 \\
1.24\end{array}$ & $\begin{array}{r}0.86 \\
.98 \\
1.07 \\
1.17\end{array}$ & $\begin{array}{r}0.10 \\
.20 \\
.50 \\
.10 \\
1.00\end{array}$ & $\begin{array}{r}0.083 \\
.285 \\
.318 \\
.114 \\
1.000\end{array}$ & $\begin{array}{r}0.083 \\
.302 \\
.611 \\
.141 \\
\approx .14\end{array}$ \\
\hline
\end{tabular}

From the results of this study the following conclusions were reached:

(1) Parabolic profile modification appears to be less sensitive to manufacturing errors than linear modification and is therefore a better choice for highcontact-ratio gears.

(2) The dynamic response of high-contact-ratio gears with linear profile modification is more sensitive to changes in the amount of modification and the length of the modification zone than is that of gears with parabolic modification.

(3) Cears with parabolic profile modification require a slightly greater amount of modification and a longer modification zone than the conventional value to minimize dynamic effects.

(4) Gears with linear profile modification require less than the conventional amount of modification and a shorter modification zone to minimize dynamic effects.

(j) Over the range considered in this report, the length of the modification zone has a greater effect than the amount of modification on the dynamic response of high-contact-ratio gears with either linear or parabolic profile modification.

(6) The optimal design of the gear tooth profile for high-contact-ratio gears involves a tradeoff between minimizing the dynamic load and minimizing the dynamic tooth root stress.

\section{REFERENCES}

1. Welbourn, D.B., 1979, "Fundamental Knowledge of Gear Noise - A Survey," Noise and Vibrations of Engines and Transmissions, Hechanical Engineering Publications, London, pp. 9-14.

2. Coy, J.J., Townsend, D.P., and Coe, H.H., 1988, "Result of NASA/Army Transmission Research," NASA/Army Rotocraft Technology, Volume 2: Materials and Structures, Propulsion and Drive Systems, Flight Dynamics and Control, and Acoustics, NASA CP-2495-VOL-2, pp. 769-801

3. Frint, H.K., 1986, "Design and Evaluat ion of High-Contact-Rat io Gearing," NASACR-17+958.

4. Cornell, R.W., and Westervelt. W.W., 1978. "Dynamic Tooth Loads and Stressing for High Contact Ratio Spur Gears," Journal of Mechanical Design. Vol. 100, No. 1, pp. 69-76.

5 Lin. H.H. 0swald. F.B., and Townsend, D.P., 1990 "Influence of Linear Profile Modification and Loading Conditions on the Dynamic Tonth Load and Stress of High Contact Ratio Gears," NASA TM-103136.

6. Lin, H.H., 1985, "Computer-Aided Design and Analysis of Spur Gear Dynamics," Ph.D. Thesis, University of Cincinnati, Cincinnati, Ohio.

7. Cornell, R., 1981, "Compliance and Stress Sensitivity of Spur Gear Teeth," Journal of Mechanical Design, Vol. 103, No. 2, pp. 447-459.

8. Kreyszig, Erwin, 1972. "Advanced Engineering Mathematics." Third Edition, John Wiley \& Sons, New York, pp. 668-670. 


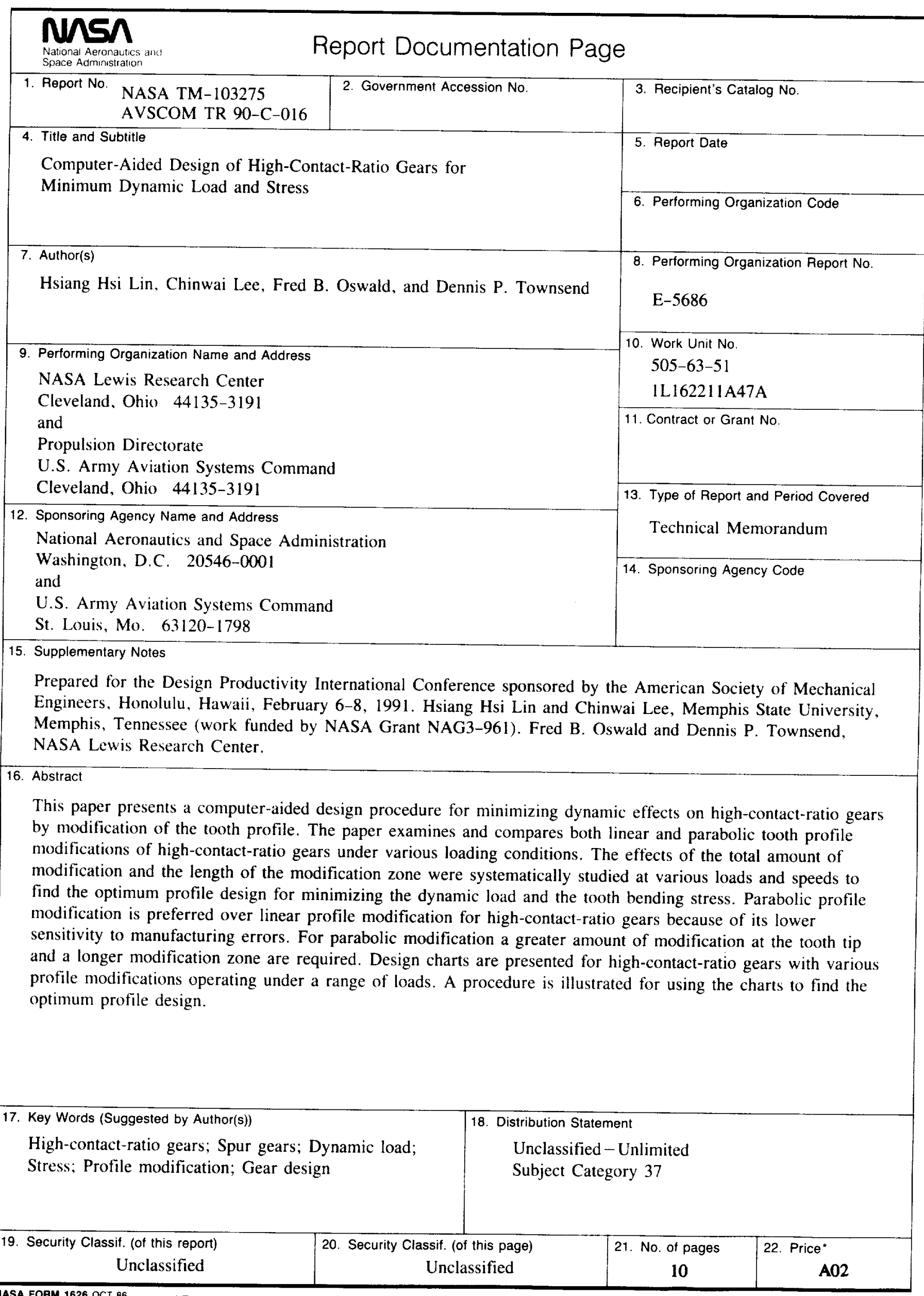



National Aeronautics and Space Administration

Lewis Research Center

Cleveland, Ohio 44135

Official Business

Penalty for Private Use $\$ 300$
FOURTH CLASS MAIL

|||||

ADDRESS CORRECTION REQUESTED

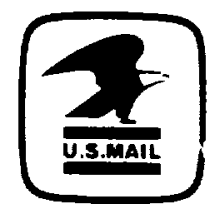

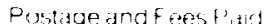

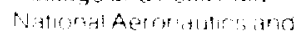
Sithe Admintstritli, th

NASTA A $A^{5}, 1$ 